650

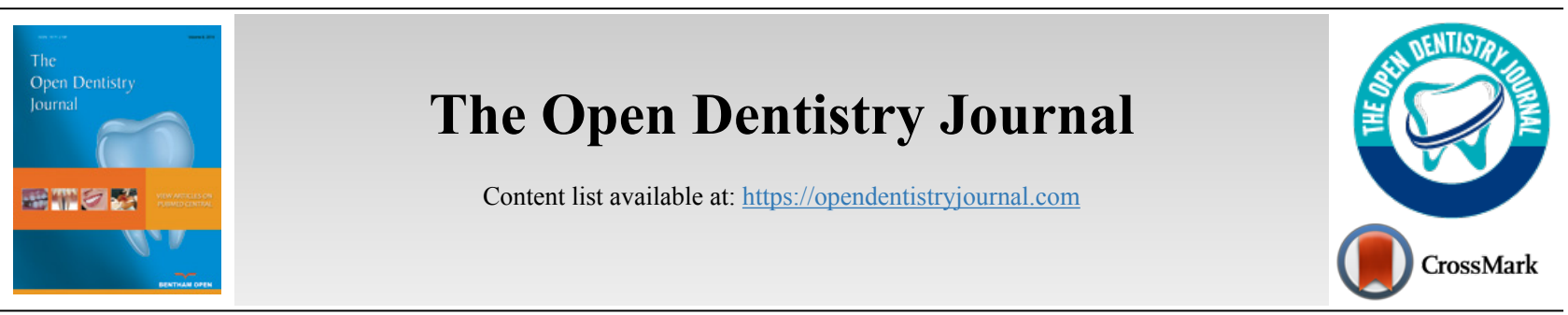

CASE REPORT

\title{
Cone Morse Implant Placement in Patients With Aids Who Use Highly Active Antiretroviral Therapy Report of Clinical Cases
}

\author{
Rafaela de Matos $^{1, *}$, Alfredo Mikail Melo Mesquita ${ }^{2}$ and Elcio Magdalena Giovani ${ }^{3}$ \\ ${ }^{1}$ Center for Studies and Special Service for Patients, Faculty of Dentistry of Paulista University, São Paulo, Brazil \\ ${ }^{2}$ Department of Prosthodontics, Faculty of Dentistry of Paulista University, São Paulo, Brazil \\ ${ }^{3}$ Department of Integrated Clinical Discipline and Patients with Special Needs, Faculty of Dentistry of Paulista University, São Paulo, Brazil
}

\begin{abstract}
:
Introduction:

The Acquired Immune Deficiency Syndrome (AIDS) is a condition that manifests itself after the infection of the human organism by the Human Immunodeficiency Virus (HIV). In 1996, the Highly Active Antiretroviral Therapy (HAART) was introduced, with the aim of slowing down the immunodeficiency and restoring the immunity of these patients, extending their life expectancy. Consequently, the need for rehabilitating dental treatments arose, aiming to improve oral health, self-esteem and the quality of life of these patients. This current study was designed to assess vertical dimensional changes in the peri-implant bone level around the placement of dental implants in AIDS patients using HAART.

\section{Materials and Methods:}

For the bone level evaluation, at first cone-beam computed tomography, panoramic radiography and periapical radiographs were used during the periods at baseline, 2, 4 and 6 months after the implant installation. The images were digitized and analyzed on programs Adobe Photoshop CS5
\end{abstract} and Digimizer 3.1.1.0.

Results:

Were installed 13 implants that presented a peri-implant bone loss average of $0.26 \mathrm{~mm}$ in the first bimester, $0.13 \mathrm{~mm}$ in the second and $0.18 \mathrm{~mm}$ in the third, totalizing a peri-implant bone loss average of $0.57 \mathrm{~mm}$ in the semester.

Conclusion:

Despite the several metabolic changes that can affect these patients due to infection, drug therapy, immune response and the absence of an adequate stability quotient and insertion torque, all implants showed osseointegration, as well as the parameters of clinical success after the installation of the implant, and the degree of bone loss in this period is within the expected according to the research.

\section{Clinical Relevance:}

Oral health professionals should be aware of the possible complications that future HIV patients may have due to their systemic and drug-related condition in association with osseointegration.

Keywords: HIV, Implant, Osseointegration, HAART, Radiographs, Software.

\begin{tabular}{|l|l|l|l}
\hline Article History & Received: July 1, 2020 & Revised: November 11, 2020 & Accepted: November 17, 2020
\end{tabular}

\section{INTRODUCTION}

The Acquired Immune Deficiency Syndrome (AIDS) is a condition that manifests itself after the human organism infection by the Human Immunodeficiency Virus (HIV). According to UNAIDS, in 2018, approximately 37.9 million people were living with HIV and there were 1,7 million new infections in the world, in Brazil, this number is around 610

\footnotetext{
* Address correspondence to this author at the Center for Studies and Special Service for Patients, Faculty of Dentistry of Paulista University, São Paulo, Brazil; Tel: 11992086647; E-mail: rafaelaodonto2010@hotmail.com
}

thousand to 1 million people living with HIV and approximately 31 to 57 thousand new HIV infections per year [1].

The HIV infection leads to a chronic and usually fatal infection that is characterized by progressive immunodeficiency, with an extended period of clinical latency, and opportunistic infections. The condition is categorized by infection and replication of HIV between T-lymphocytes expressing the CD4 antigen (helper inducer lymphocyte) [2]. In 1996, there was a new hope with the introduction of Highly Active Antiretroviral Therapy (HAART), since it was espec- 


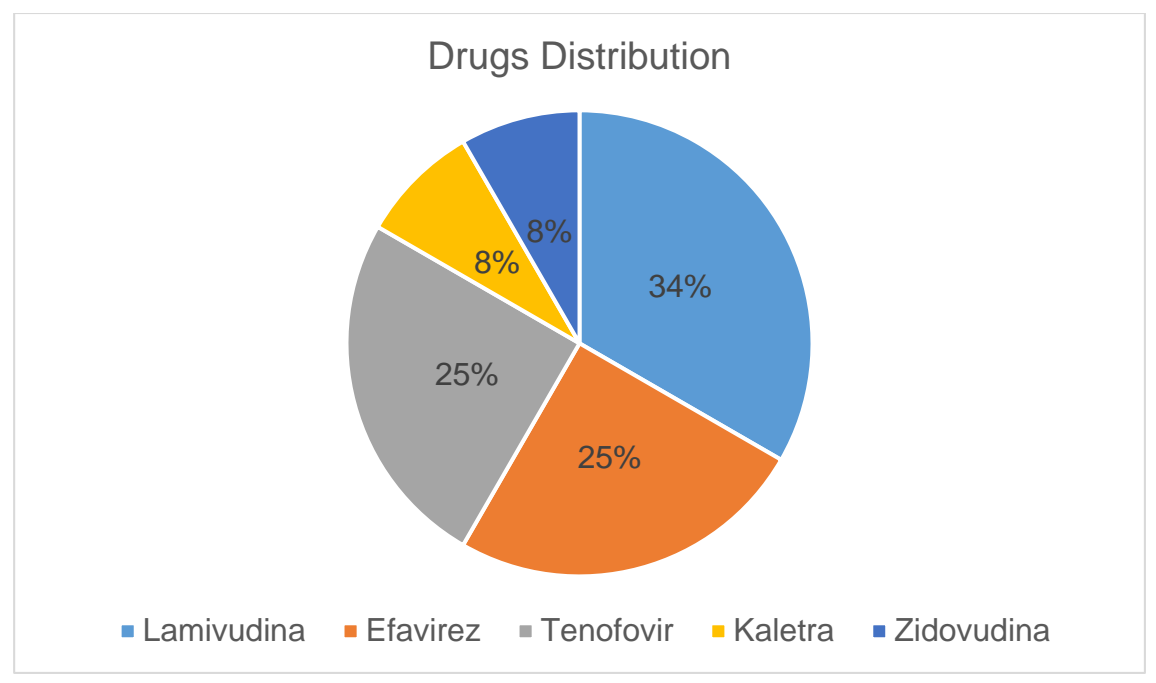

Fig. (1). Antiretroviral drugs distribution.

ially projected to the specific inhibition of viral replication through antiretroviral drugs, the main objective of which is to delay the immunodeficiency progression and/or to restore the immunity, extending the lifetime and quality of life of the infected person. However, nowadays, we have noticed a high occurrence of adverse side effects and inherent resistance to the therapy itself [2 - 6].

This is the new reality and concern faced by these professionals, since the HIV infection can be controlled, the viral load can be suppressed, the immunity can be stabilized, resulting in a higher survival rate, due to the use of an effective and lasting antiretroviral therapy. After HAART started being used, scientific findings showed that bone metabolism could be closely linked to the use of these products. The gradual bone demineralization is the characteristic of individuals infected with HIV that are treated with protease inhibitors, whereas these showed a higher chance of having a more significant bone demineralization, that can be associated with an increasing prevalence of osteopenia and osteoporosis, that can increase the risk of bone fractures in people with HIV/AIDS [7 - 14].

Individuals with Aids that are administrating HAART, showed a higher propension to have a more significant bone demineralization, that can be associated with an increasing prevalence of osteopenia and osteoporosis, increasing the risk of bone fractures and/or making the peri-implant bone formation more difficult. Therefore, the purpose of this research is to evaluate the bone level and the clinical success of the implants installed in patients with Aids who use HAART.

\section{MATERIALS AND METHODS}

The research project was approved by the Research Ethics Committee of Paulista University (UNIP), under opinion number 1322411. There were selected patients who seek care at the Center for Study and Care of Special Patients (CEAPE) and Implantology Course/Credit of the Postgraduation Program and Research of UNIP (FOUNIP). The research was conducted at the CEAPE of Paulista University Dentistry Faculty (Fig. 1).
The patient should be in AIDS and administrating highly active antiretroviral therapy (HAART), not having at least one tooth and present satisfactory oral and general health. All patients underwent a complete clinical examination, including anamnesis, physical examination and laboratory tests. Before the surgical procedures, the patients were molded for the case planning and surgical guides were made, which were used in the implant placement surgery.

Before installing the implants, the following procedures were performed: extra-oral antisepsis of the patient with chlorhexidine $2 \%$, intra-oral antisepsis with chlorhexidine $0.12 \%$ (rinsing the mouth for 1 minute), surgical field assembly and sterile field placement, local anesthesia (lidocaine $2 \%$ with vasoconstrictor), linear incision over the border and mucoperiosteal flap detachment. The bone perforation for the implant installation was conducted according to the manufacture's instruction.

The patients were medicated with amoxicillin 500mg: 1 tablet every 8 hours during 7 days, with the first double dose being administered 1 hour before the surgery; dexamethasone 4mg: 1 tablet every 24 hours during 3 days, with the first dose being administered 1 hour before the surgery; and paracetamol 750mg: 1 tablet every 8 hours during 3 days, in case of pain (Fig. 2).

The patients who underwent implant placement surgery were instructed to avoid mechanical cleaning in the operated region. To clean the region, mouthwashes with $0.12 \%$ chlorhexidine were instituted twice daily, for 7 days. Nylon sutures were removed 10 days after surgery.

After 6 months, the procedures of prosthetic components selection, components installation and molding for the manufacture of screwed metal-ceramic crowns were perfomed.

\subsection{Evaluated Parameters}

\subsubsection{Bone Loss}

The radiographic control was performed by periapical radiographs taken immediately after implant placement and 
during the following periods after the surgery: 2,4 and 6 months. As level bone evaluation reference was used, the peri- implant bone of the mesial and distal sides were found in periapical radiographs (Figs. 3, 4).

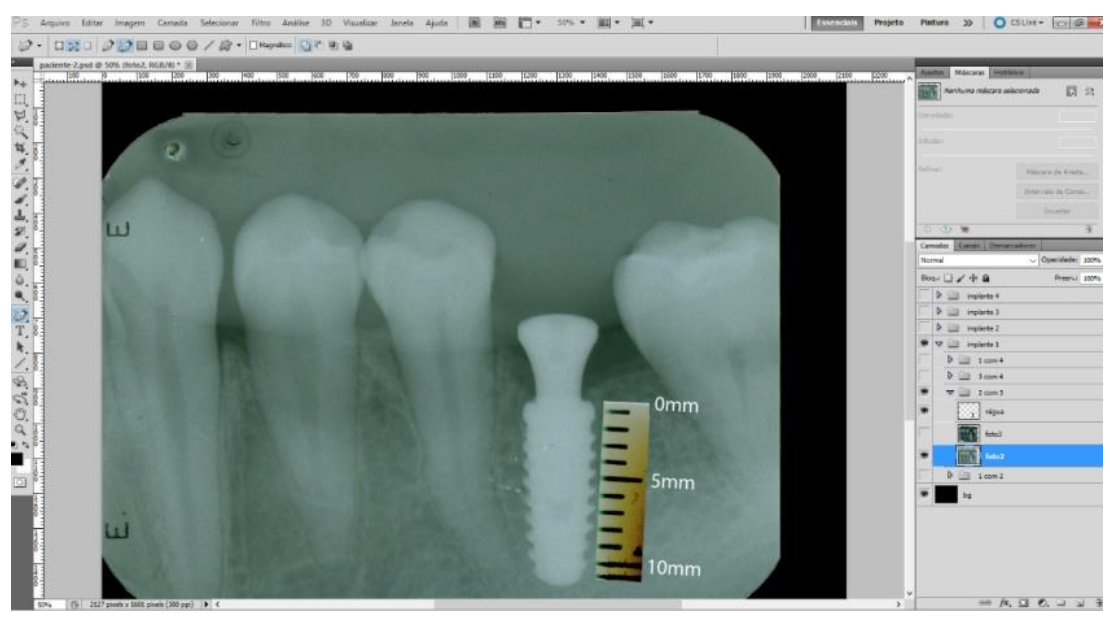

Fig. (2). Image inserted on Photoshop it was marked the bone level on the mesial and distal side of the implant for future comparison.

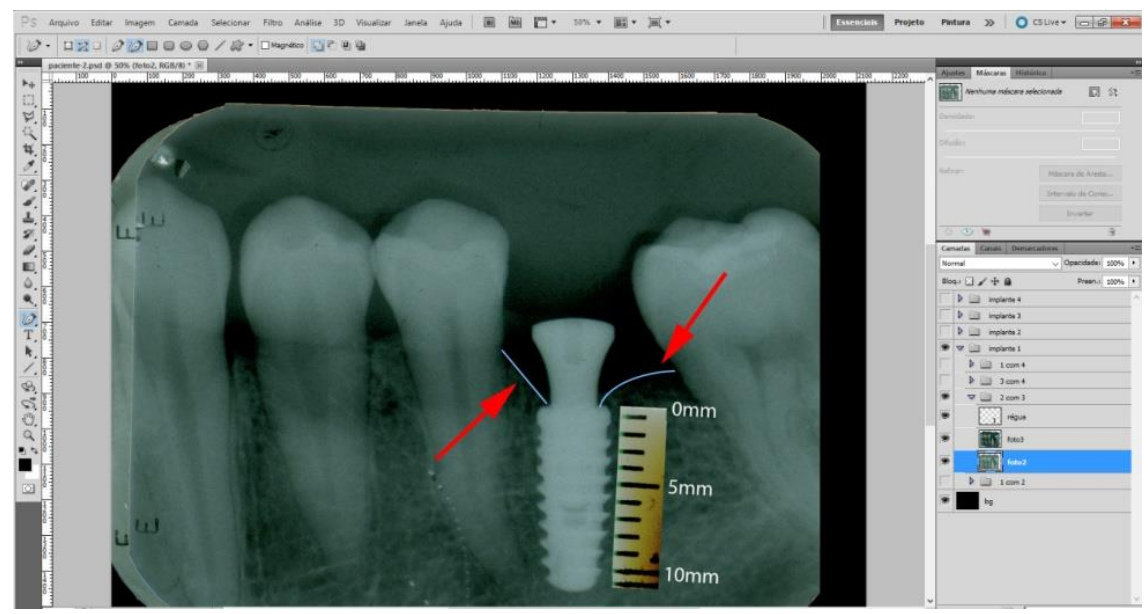

Fig. (3). After we superpose the latest radiograph.

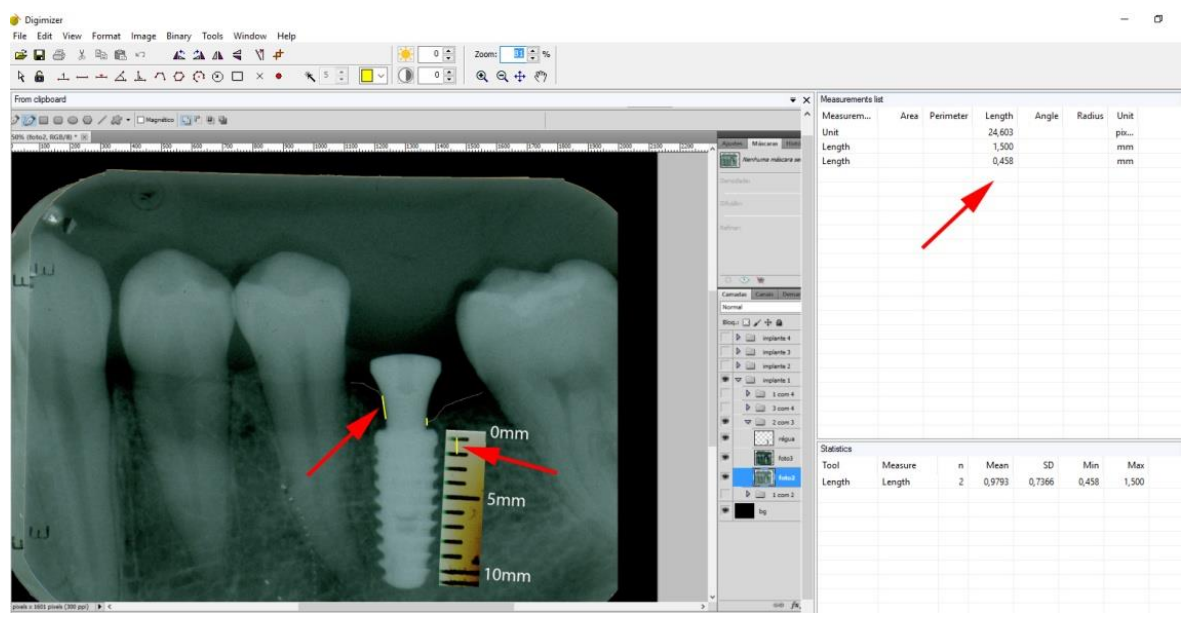

Fig. (4). We put the result of the superposition to the Digimizer software, for bone loss calibration and measurement. 


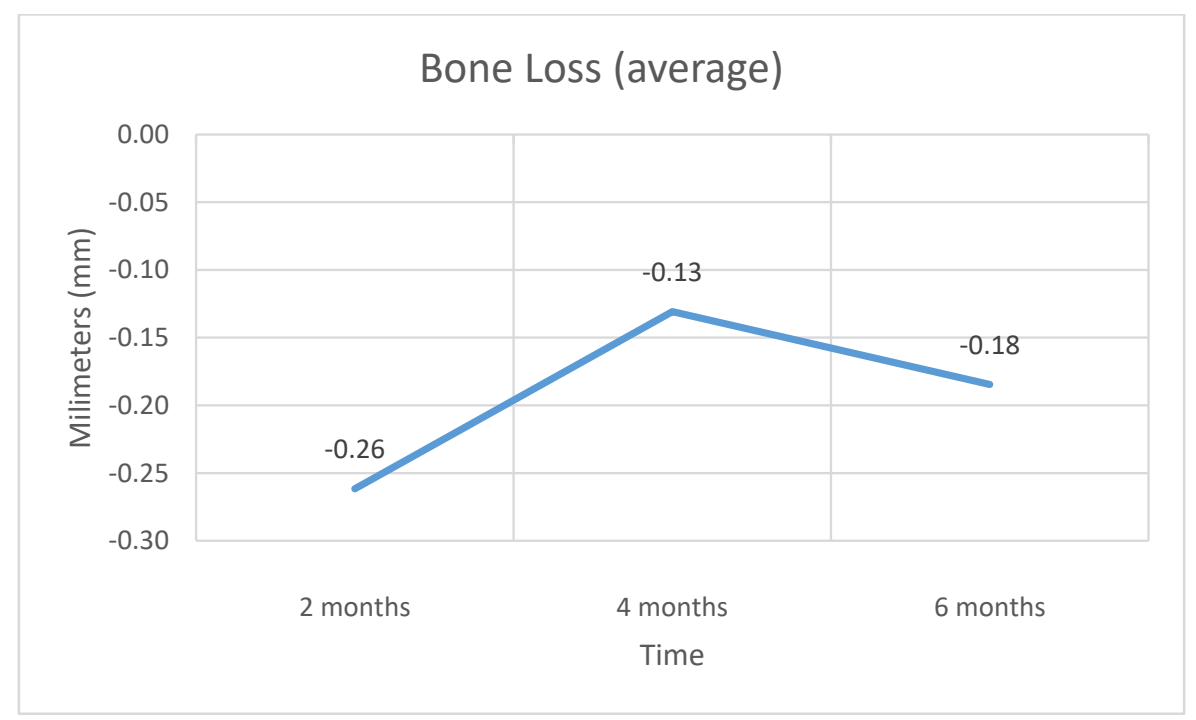

Fig. (5). Bone loss (average).

The periapical radiographs were obtained using the parallelism technique by an individualization (bite guide) of the radiographic positioning (Cone Est. Química - Maquira), using a condensation silicone (Optosil- Comfort Putty) at the teeth support site, making the patient biting always in the same position. Radiographic film (Contrast Speed E-DFL) was used with SpectroII X-ray equipment (Dabi-Atlante, Brazil), with a peak kilovoltage fixed at 67 , an exposure time of 0.6 seconds and fixed milliamps at $8 \mathrm{~mA}$.

The periapical radiographs images, generated in the chemical radiographic processing, were made using the temperature-time method. These images were obtained and transferred to a computer with a Scanner HP-Scanjet G4050, in order to analyse them using the programs Adobe PhotoshopCS5 and Digimizer version 3.1.1.0, getting linear measurements of vertical peri-implant marginal bone levels converting pixels to millimetres. After 6 months, the implants must present clinical patterns of success, such as the absence of pain, infection, mobility and continuous radiolucency around the implant (Fig. 5).

\section{RESULTS}

The patients were screened at CEAPE FOUNIP, resulting in a total of 13 installed implants.

During the evaluations on the periods of 2, 4 and 6 months, the patients reported the absence of pain and the absence of infection, mobility and continuous radiolucency around the implant were clinically observed. No implant was lost during the evaluation period.

\section{DISCUSSION}

After the introduction of HAART, in 1996, the AIDS development parameters, which occur after the human organism infection by HIV, experienced a significant change. HAART has the purpose of slowing down the immunodeficiency and restoring immunity. Thereby, patients who use this therapy have a higher survival rate and better quality of life, creating, then, the need for rehabilitative treatments for this group of patients. Despite several positive aspects, this therapy has side effects that can be enhanced by infection, such as changes in bone metabolism [2 - 6].

This study had a sample of 13 implants, with an average age of 45 years. All patients use Lamivudine (nucleoside analogue reverse transcriptase inhibitors), $25 \%$ of patients use Efavirenz (non-nucleoside analogue reverse transcriptase inhibitors), $25 \%$ of patients use Tenofovir (nucleotide analogue reverse transcriptase inhibitors), $8 \%$ of patients use Zidovudina and Kaletra (protease inhibitors). These drugs can cause several clinical changes, such as metabolic disorders, cardiovascular diseases, changes in liver and kidney functions, decreased cognition and changes in bone metabolism, like osteopenia and osteoporosis [15 - 18]. However, all patients were within normal limits, determined by laboratory tests.

According to the literature, HAART may be associated with an increased prevalence of osteopenia and osteoporosis, which can raise the risk of bone fractures in people with HIV/AIDS [7 - 14], as well as altering the bone/implant osseointegration relationship, promoting the development of peri-implantitis and/or loss of the implant. Therefore, this study assessed the peri-implant bone level using periapical radiographs, in addition to clinical evaluation. According to the criteria established by the European Commission (2012), computed tomography after implant installation should only be performed in cases where it is necessary to assess complications such as nerve damage and infections. For routine exams, the most suitable protocol is periapical radiography [19].

In this research, cone morse connection implants were used, that, according to researchers [20 - 22], have a reduced platform that minimizes the bone loss around the implants, that can occur by reducing bacterial infiltration and bone crest tension due to a better distribution of masticatory strength, 
which is very important since these patients are more likely to have bone resorption.

The results obtained at baseline and 2 months demonstrate an average bone loss of $0.26 \mathrm{~mm}$, in the period of 2 and 4 months, the average bone loss was $0.13 \mathrm{~mm}$ and in the period of 4 and 6 months, the average bone loss was $1.18 \mathrm{~mm}$. The average total bone loss was $0.57 \mathrm{~mm}$, which supports established researches that showed a 1.5 to $2.0 \mathrm{~mm}$ periimplant loss after the first year of installation in normoreactive patients [23 - 25].

There are not many studies related to the installation of implants in patients with HIV, but despite this, it was possible to find two studies. A study carried out in 2012 reported that the average bone loss in a group of patients who were using HAART with the protease inhibitor was $0.49 \mathrm{~mm}$, and in the group who was using HAART without the protease inhibitor, the average bone loss was $0.47 \mathrm{~mm}$, within one year [26], indicating that our study shows a higher bone level loss.

However, another study published in 2016 showed that the average peri-implant bone loss in patients with HIV was 1.19 $\mathrm{mm}$ in one year [27], which shows greater bone loss than our study, but this could have happened due to the shorter followup time of the study. It is worth mentioning that, in this study, the highest level of bone loss, when compared to the number of CD4 T cells, proved to be inversely proportional, that is, the greater the number of cells, the lower the level of loss.

Currently, the appropriate parameters to measure implant stability are the implant stability quotient and the insertion torque $[28,29]$. Typically, the implant stability quotient scale ranges from 40 to 80 [30]. Due to the bone quality found at the time of surgery, all 13 implants reached implant stability quotient $<40$ and insertion torque $<20 \mathrm{~N} / \mathrm{cm}$. Despite this, during the first 6 months after the surgery, all implants were osseointegrated.

The cause of periodontitis is an integral part of a multifactorial condition. The presence of subgingival biofilm, together with a different immune response from the host, may be essential for the development of this disease [31, 32]. Due to the combination of factors and mainly to the possible different immune response from the hosts to an inflammatory process, which can potentiate and accelerate that situation, the motivation of the patient and in conjunction with the procedures performed by the oral health team, it is extremely important to control the bacterial plaque, which is a factor that can be controlled and, consequently, can improve the inflammatory response of individuals who have metabolic and immunological changes.

In addition, the clinical parameters of the absence of pain, infection, mobility and continuous radiolucency around the implant were noticed in the clinical examination of patients, confirming the criteria established since the 1980s [26, 33].

\section{CONCLUSION}

Despite the various metabolic changes that can affect these patients due to infection, drug therapy, immune response and the absence of an adequate stability quotient and insertion torque, all implants showed osseointegration, as well as the parameters of clinical success after implant installation, and the level of bone loss in this period is within the expected according to the research. This research needs to have a longer follow-up time, as well as a larger number of patients to validate the purpose of this study.

\section{ETHICS APPROVAL AND CONSENT TO PARTICIPATE}

The research project was approved by the Research Ethics Committee of Paulista University (UNIP), Brazil under opinion number 1322411.

\section{HUMAN AND ANIMAL RIGHTS}

No animals were used in this research. All human research procedures followed were in accordance with the ethical standards of the committee responsible for human experimentation (institutional and national), and with the Helsinki Declaration of 1975, as revised in 2013.

\section{CONSENT FOR PUBLICATION}

Not applicable.

\section{STANDARD OF REPORTING}

CARE guidelines and methodology were followed.

\section{FUNDING}

None.

\section{CONFLICT OF INTEREST}

The author declares no conflict of interest, financial or otherwise.

\section{ACKNOWLEDGEMENTS}

Declared none.

\section{REFERENCES}

[1] UNAIDS 2018. Available at: http://unaids.org.br Accessed on July 30

[2] Passaes CP, Sáez-Cirión A. HIV cure research: Advances and prospects. Virology 2014; 454-455: 340-52

[http://dx.doi.org/10.1016/j.virol.2014.02.021] [PMID: 24636252]

[3] Kilsztajn S, Lopes ES, do Carmo MS, Rocha PA. Improvement in survival among symptomatic AIDS patients by exposure category in Sao Paulo. J Acquir Immune Defic Syndr 2007; 45(3): 342-7. [http://dx.doi.org/10.1097/QAI.0b013e31806910ff] [PMID: 17496563]

[4] Cunha A. HIV Infection.Antibiotic Essentials Massachussets. Physician's Press 2009; 8: p. 273.

[5] Hendrickson SL, Kingsley LA, Ruiz-Pesini E, et al. Mitochondrial DNA haplogroups influence lipoatrophy after highly active antiretroviral therapy. J Acquir Immune Defic Syndr 2009; 51(2): 111-6.

[http://dx.doi.org/10.1097/QAI.0b013e3181a324d6]

[PMID: 19339895]

[6] Moran CA, Weitzmann MN, Ofotokun I. The protease inhibitors and HIV-associated bone loss. Curr Opin HIV AIDS 2016; 11(3): 333-42. [http://dx.doi.org/10.1097/COH.0000000000000260] [PMID: 26918650]

[7] Cabrero E, Griffa L, Burgos A. Prevalence and impact of body physical changes in HIV patients treated with highly active antiretroviral therapy: Results from a study on patient and physician perceptions. AIDS Patient Care STDS 2010; 24(1): 5-13. [http://dx.doi.org/10.1089/apc.2009.0191] [PMID: 20095903]

[8] Tebas P, Powderly WG, Claxton S, et al. Accelerated bone mineral 
loss in HIV-infected patients receiving potent antiretroviral therapy. AIDS 2000; 14(4): F63-7.

[http://dx.doi.org/10.1097/00002030-200003100-00005] [PMID: 10770534]

[9] Lima AL, Zumiotti AV, Camanho GL, et al. Osteoarticular complications related to HIV infection and highly active antiretroviral therapy. Braz J Infect Dis 2007; 11(4): 426-9.

[http://dx.doi.org/10.1590/S1413-86702007000400012] [PMID: 17873999]

[10] Caputo BV, Traversa-Caputo GC, Costa C, Giovani EM. Evaluation of bone alterations in the jaws of HIV-infected menopausal women. Braz Oral Res 2013; 27(3): 231-7.

[http://dx.doi.org/10.1590/S1806-83242013005000014] [PMID: 23657485]

[11] Ferreira CE, Pinto-Neto AM, Conde DM, Costa-Paiva L, Morais SS, Magalhães J. Menopause symptoms in women infected with HIV: Prevalence and associated factors. Gynecol Endocrinol 2007; 23(4): 198-205.

[http://dx.doi.org/10.1080/09513590701253743] [PMID: 17505939]

[12] Dong HV, Cortés YI, Shiau S, Yin MT. Osteoporosis and fractures in HIV/hepatitis C virus coinfection: A systematic review and metaanalysis. AIDS 2014; 28(14): 2119-31.

[http://dx.doi.org/10.1097/QAD.0000000000000363] [PMID: 24977441]

[13] Barber TJ, Moyle G, Hill A, et al. A cross-sectional study to evaluate the association of hyperbilirubinaemia on markers of cardiovascular disease, neurocognitive function, bone mineral density and renal markers in HIV-1 infected subjects on protease inhibitors. HIV Clin Trials 2016; 17(3): 123-30.

[http://dx.doi.org/10.1080/15284336.2016.1176305] [PMID: 27125367]

[14] Brown TT, Mallon PW. Editorial: Working towards an understanding of bone disease in HIV. Curr Opin HIV AIDS 2016; 11(3): 251-2. [http://dx.doi.org/10.1097/COH.0000000000000277] [PMID: 27045192]

[15] Aberg JA. Aging, inflammation, and HIV infection. Top Antivir Med 2012; 20(3): 101-5.

[PMID: 22954610]

[16] Smit M, Brinkman K, Geerlings S, et al. Future challenges for clinical care of an ageing population infected with HIV: A modelling study. Lancet Infect Dis 2015; 15(7): 810-8.

[http://dx.doi.org/10.1016/S1473-3099(15)00056-0] [PMID: 26070969]

[17] Rey D, Treger M, Sibilia J, et al. Bone mineral density changes after 2 years of ARV treatment, compared to naive HIV-1-infected patients not on HAART. Infect Dis (Lond) 2015; 47(2): 88-95.

[http://dx.doi.org/10.3109/00365548.2014.968610] [PMID: 25426996]

[18] Yin MT, Falutz J. How to predict the risk of fracture in HIV? Curr Opin HIV AIDS 2016; 11(3): 261-7.

[http://dx.doi.org/10.1097/COH.0000000000000273] [PMID: 26918651]

[19] European Commission. Radiation Protect $n{ }^{\circ} 172$ Cone Beam CT for Dental and Maxillofacial Radiology 2012. Available from: http://www.sedentexct.eu/content/guidelines-cbct-dental-and-maxillof acial-radiology

[20] Pieri F, Aldini NN, Marchetti C, Corinaldesi G. Influence of implantabutment interface design on bone and soft tissue levels around immediately placed and restored single-tooth implants: A randomized controlled clinical trial. Int J Oral Maxillofac Implants 2011; 26(1): 169-78.

[PMID: 21365053]

[21] Annibali S, Bignozzi I, Cristalli MP, Graziani F, La Monaca G,
Polimeni A. Peri-implant marginal bone level: A systematic review and meta-analysis of studies comparing platform switching versus conventionally restored implants. J Clin Periodontol 2012; 39(11): 1097-113.

[http://dx.doi.org/10.1111/j.1600-051X.2012.01930.x]

[PMID: 22931292]

[22] Gultekin BA, Gultekin P, Leblebicioglu B, Basegmez C, Yalcin S. Clinical evaluation of marginal bone loss and stability in two types of submerged dental implants. Int J Oral Maxillofac Implants 2013; 28(3): 815-23.

[http://dx.doi.org/10.11607/jomi.3087] [PMID: 23748314]

[23] Adell R, Lekholm U, Rockler B, Brånemark PI. A 15-year study of osseointegrated implants in the treatment of the edentulous jaw. Int $\mathrm{J}$ Oral Surg 1981; 10(6): 387-416.

[http://dx.doi.org/10.1016/S0300-9785(81)80077-4] [PMID: 6809663]

[24] Cochran DL, Hermann JS, Schenk RK, Higginbottom FL, Buser D. Biologic width around titanium implants. A histometric analysis of the implanto-gingival junction around unloaded and loaded nonsubmerged implants in the canine mandible. J Periodontol 1997; 68(2): 186-98. [http://dx.doi.org/10.1902/jop.1997.68.2.186] [PMID: 9058338]

[25] Hermann JS, Cochran DL, Nummikoski PV, Buser D. Crestal bone changes around titanium implants. A radiographic evaluation of unloaded nonsubmerged and submerged implants in the canine mandible. J Periodontol 1997; 68(11): 1117-30. [http://dx.doi.org/10.1902/jop.1997.68.11.1117] [PMID: 9407406]

[26] Albrektsson T, Zarb G, Worthington P, Eriksson AR. The long-term efficacy of currently used dental implants: A review and proposed criteria of success. Int J Oral Maxillofac Implants 1986; 1(1): 11-25. [PMID: 3527955]

[27] Gherlone EF, Capparé P, Tecco S, et al. Implant Prosthetic Rehabilitation in Controlled HIV-Positive Patients: A Prospective Longitudinal Study with 1-Year Follow-Up. Clin Implant Dent Relat Res 2016; 18(4): 725-34.

[http://dx.doi.org/10.1111/cid.12353] [PMID: 25955953]

[28] Sennerby L, Meredith N. Implant stability measurements using resonance frequency analysis: Biological and biomechanical aspects and clinical implications. Periodontol 2000 2008; 47(1): 51-66.

[http://dx.doi.org/10.1111/j.1600-0757.2008.00267.x] [PMID: 18412573]

[29] Lages FS, Douglas-de Oliveira DW, Costa FO. Relationship between implant stability measurements obtained by insertion torque and resonance frequency analysis: A systematic review. Clin Implant Dent Relat Res 2018; 20(1): 26-33.

[http://dx.doi.org/10.1111/cid.12565] [PMID: 29194944]

[30] Bavetta G, Bavetta G, Randazzo V, et al. A Retrospective Study on Insertion Torque and Implant Stability Quotient (ISQ) as Stability Parameters for Immediate Loading of Implants in Fresh Extraction Sockets. BioMed Res Int 2019; 2019: 9720419.

[http://dx.doi.org/10.1155/2019/9720419] [PMID: 31781659]

[31] Cantore S, Mirgaldi R, Ballini A, et al. Cytokine gene polymorphisms associate with microbiogical agents in periodontal disease: Our experience. Int J Med Sci 2014; 11(7): 674-9.

[http://dx.doi.org/10.7150/ijms.6962] [PMID: 24843315]

[32] Ballini A, Santacroce L, Cantore S, et al. Probiotics Efficacy on Oxidative Stress Values in Inflammatory Bowel Disease: A Randomized Double-Blinded Placebo-Controlled Pilot Study. Endocr Metab Immune Disord Drug Targets 2019; 19(3): 373-81.

[http://dx.doi.org/10.2174/1871530319666181221150352] [PMID: 30574857]

[33] Smith DE, Zarb GA. Criteria for success of osseointegrated endosseous implants. J Prosthet Dent 1989; 62(5): 567-72. [http://dx.doi.org/10.1016/0022-3913(89)90081-4] [PMID: 2691661]

\section{(C) 2020 de Matos et al.}

This is an open access article distributed under the terms of the Creative Commons Attribution 4.0 International Public License (CC-BY 4.0), a copy of which is available at: (https://creativecommons.org/licenses/by/4.0/legalcode). This license permits unrestricted use, distribution, and reproduction in any medium, provided the original author and source are credited. 